\title{
Specificity in parasites with multiple hosts: The view from the hosts' perspective
}

\section{George A. Lozano}

George A. Lozano (dr.george.lozano@gmail.com), Estonian Centre of Evolutionary Ecology, Tartu, Estonia

Reminiscent of Dawkins' analogy using the Necker cube (Dawkins 1983), Forbes and Mlynarek (2014) offer us a different perspective of multi-host parasite systems. Forbes and Mlynarek point out that, traditionally, multi-host parasite systems have been mostly viewed from the perspective of the parasite. Parasites have shorter lifespans and hence, supposedly have the upper hand in the antagonistic coevolutionary race between parasites and host. It is logical to study the problem from the perspective of the party that is more likely to be better adapted. However, Forbes and Mlynarek suggest it is perhaps time to view the problem from the perspective of the hosts, and offer a hypothesis based on the degree of gene flow between host populations affected or unaffected by a given parasite. Forbes and Mlynarek's 'coevolutionary release hypothesis' argues that when some host populations are not exposed to the parasite, gene flow from the unaffected host population hinders the affected host population's ability to evolve resistance to the parasite.

The hypothesis is sound, intuitive, and perhaps long overdue, yet surprisingly, Forbes and Mlynarek are tentative with their predictions, and choose not to fully explore the implications of their idea. They limit their predictions and discussion to the differences in parasite recognition and immunity among host populations. However, the process of parasite resistance is multifaceted and consists of several other layers of protection besides physiological or immunological adaptations. Here, I shall briefly speculate on how the coevolutionary release hypothesis can affect several other related areas, and I shall explore specific predictions and implications of examining multi-host systems from the hosts' perspective.

Behaviour is the first layer of protection against parasitism. Anti-parasitic behaviours are wide-ranging, and include, for example, avoiding infected individuals, simple preening and grooming, avoiding parasite-laden areas or food items, and even self-medication (Hart 1990, Villalba and Provenza 2009, Moore et al. 2013). Many of these behavioural defenses against parasites are learned, and many others are innate. The coevolutionary release hypothesis makes clear predictions about the degree and effectiveness of parasite-avoiding and parasite-defensive behaviours among host populations. The hypothesis predicts that the most effective parasiteprotection behaviours should evolve only in closed populations in which all potential hosts are exposed to the parasite, rather than in open populations. In contrast, the hypothesis makes no predictions about learned defenses - whether or not the host population is open or closed.

For at least 30 years now, parasites have featured prominently in the study of sexual selection (Andersson 1994). There is no need here for an extensive review of the main hypotheses, but suffice it to say that, via various mechanisms, parasite resistance is thought to be indicated by ornamental colours and behaviours, which are hence important in mate selection. Populations differ in the degree to which they express sexual ornaments and these differences have been attributed to predation, parasite prevalence, condition, and other factors (e.g., Hill 1993, Baird et al. 1997, Magurran 1998). Forbes and Mlynarek add another possible cause for differences in the expression of sexual ornaments, in this case, among closely related species. The hypothesis predicts that closed populations - those not connected to populations not exposed to a given parasite-should develop the strongest resistance, and by extension, should have the most developed sexual ornaments. The relationship between ornaments and resistance can come about via several mechanisms, so if the main prediction is confirmed, several other research avenues become available. 
The coevolutionary release hypothesis addresses inter-specific differences in parasite resistance. Hence, the hypothesis might also be important for zoonoses in which several species can act as reservoirs. Differences in resistance among reservoir populations are crucial to understanding the spread of the parasites, and the susceptibility and threat of reservoir populations (Daszak et al. 2000, Kramer et al. 2008). Considerable effort is dedicated to monitoring potential reservoir populations. The coevolutionary release hypothesis, if supported, might also add a level of complexity to these efforts by pinpointing the species that are most likely to be affected.

In summary, Forbes and Mlynarek's coevolutionary release hypothesis opens up several other avenues of research aside from the ones mentioned in their paper. It is possible to formulate predictions relevant to energetics, pathogen recognition at the molecular level, conservation biology, etc. Surely many other implications will reveal themselves as researchers begin to think of the hypothesis as it applies to their specific system. Perhaps some caveats might be useful. Currently, the hypothesis is framed along a single system whereby one parasite infects two or more related species, a situation that seldom occurs. Therefore, more extensive mathematical modeling might be necessary, as long, of course, as the resulting models remain accessible to the empiricists. Furthermore, the hypothesis does not negate other effects; hence, tests will have to be carefully designed along lines of mutually exclusive predictions. The hypothesis offers an exciting new way of viewing intraspecific differences in parasite resistance.

\section{Acknowledgements}

I thank the University of Tartu for giving me free access to their online collections. This is contribution number 1409 of the ECEE (reg no. 80355697).

\section{References}

Andersson, M. 1994. Sexual Selection. Princeton University Press, Princeton, NJ.

Baird, T.A., Fox, S.F., and J.K. McCoy. 1997. Population differences in the roles of size and coloration in intra- and intersexual selection in the collared lizard, Crotaphytus collaris: Influence of habitat and social organization. Behavioral Ecology 8:506-517. CrossRef

Daszak, P., Cunningham, A.A., and A.D. Hyatt. 2000. Emerging infectious diseases of wildlife - Threats to biodiversity and human health. Science 287:443-449. CrossRef

Dawkins, R. 1983. The extended phenotype. Oxford University Press, Oxford.
Forbes, M.R., and J.J. Mlynarek. 2014. A hypothesis to explain host species differences in resistance to multihost parasites. Ideas in Ecology and Evolution 7: 1724. CrossRef

Hart, B.L. 1990. Behavioural adaptations to pathogens and parasites: five strategies. Neuroscience \& Biobehavioral Reviews 14:273-294. CrossRef

Hill, G.E. 1993. Geographic variation in the carotenoid plumage pigmentation of male house finches (Carpodacus mexicanus). Biological Journal of the Linnean Society 49:63-86. CrossRef

Kramer, L.D., Styer, L.M., and G.D. Ebel. 2008. A global perspective on the epidemiology of West Nile virus. Annual Review of Entomology 53: 61-81. CrossRef

Magurran, A.E. 1998. Population differentiation without speciation. Philosophical Transactions of the Royal Society B: Biological Sciences 353:275-286. CrossRef

Moore, B.D., Foley, W.J., Forbey, J.S., and J.L. Degabriel. 2013. Self-medication: a learning process? Science 340:1041. CrossRef

Villalba, J.J., and F.D. Provenza. 2009. Learning and dietary choice in herbivores. Rangeland Ecology \& Management 62:399-406. $\underline{\text { CrossRef }}$ 